\title{
Formação em Psicologia e Vulnerabilidade Social: Um Estudo das Expectativas de Inserção Profissional de Formandos
}

Psychology training and social vulnerability: a study of students' expectancies of professional insertion

Silvia Maria Silveira \& Henrique Caetano Nardi

Universidade Federal do Rio Grande do Sul

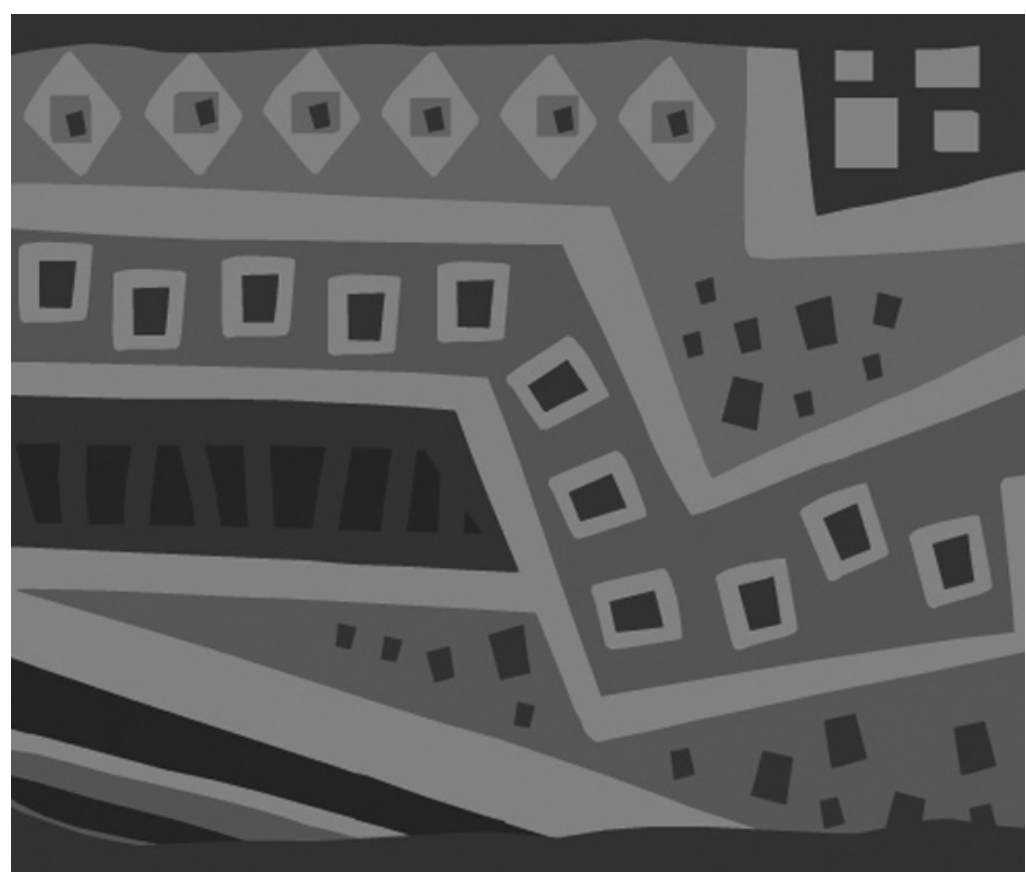


Resumo: Este trabalho busca compreender como se construíram as expectativas de inserção profissional de formandos em Psicologia de uma universidade privada do interior do Rio Grande do Sul. Utilizamos como suporte teórico as contribuições de Michel Foucault e Robert Castel. As entrevistas foram realizadas seguindo a metodologia das trajetórias de vida conforme descrição de Robert Cabanes e Daniel Bertaux, buscando estabelecer relações entre estas, o trabalho e a construção do ideal profissional. Foram realizadas seis entrevistas não estruturadas, que seguiram o modelo da abordagem biográfica. As conclusões apontam a distância entre o ideal de uma formação centrada na clínica como forma de ascensão social e a realidade do mercado e as condições de vulnerabilidade das trajetórias desse grupo em particular.

Palavras-chave: Formação em psicologia. Trajetórias de vida. Vulnerabilidade social. Inserção profissional.

Abstract: This article aims at understanding the expectancies of the professional insertion construction of a group of students in the end of their Psychology training in a countryside university of Rio Grande do Sul State. We used as theoretical support the contributions of Michel Foucault and Robert Castel. The interviews were conducted according to the methodology of life trajectories, as described by Robert Cabanes and Daniel Bertaux, in order to establish the relationship among the trajectories, the labor market and the construction of the professional ideal. We conducted 6 open interviews that followed the biographical approach technique. The conclusions reveal the distance between the ideal of training based on clinical skills associated to social upgrade and to the labor market's reality and to the social vulnerability of the trajectories of this particular group.

Keywords: Psychology training. Life trajectories. Social vulnerability. Professional insertion.

O objetivo deste artigo é compreender a expectativa de inserção profissional de formandos de Psicologia numa pequena região do interior do Estado e dentro de um curso em particular, no caso, o curso de Psicologia. O estudo faz parte de uma preocupação mais ampla e diz respeito à forma como estão ocorrendo os processos de individualização ligados às transformações do mundo do trabalho, na sociedade neoliberal, tais como desregulamentação, exigência de novas competências, e, em particular, redução de vagas e renda para indivíduos com terceiro grau completo. Cabe assinalar que, de acordo com Foucault (2001a), a forma "indivíduo" é aquela assumida pelos sujeitos a partir da modernidade, forma essa que se acentua no neoliberalismo; assim, ao nos referirmos à constituição dos sujeitos, podemos também falar em processos de individualização.

No caso do Brasil, conforme descrevemos em outro momento (Nardi, 2006), os efeitos perversos da globalização têm intensificado as desigualdades, com o aumento do desemprego e com o declínio da eficácia e da qualidade dos serviços públicos. A Universidade, enquanto instituição, em sua origem pública e de missão social, não fica imune aos efeitos deletérios do neoliberalismo.

A partir dos anos 90, houve uma redução do investimento público em educação, 
concomitantemente ao enfraquecimento do Estado, e, na América Latina, de uma forma geral, ocorreu uma profunda redefinição do papel do Estado do ponto de vista educacional, que se distanciou da função de educar para aproximar-se da função fiscalizadora, como afirma Gentili (2001). No caso do Brasil, essa transformação funcional do Estado em relação à educação se evidencia com o advento dos chamados "provões", os quais, segundo Trindade (2001), se prestam mais como ferramenta classificatória, que prepara o terreno para a legitimação do financiamento do ensino privado, do que como fator de melhoria do ensino de graduação.

Ainda como corolário da falta de investimento público em educação, associado ao processo de massificação do ensino de graduação, conforme relembra Trindade (2001), ocorreu

Os formandos em questão fazem parte de um contingente de indivíduos que partilham instituições, comunidades, escolas, universidades, enfim, elementos diversos, que, tal qual num jogo, mudam de posição, modificam suas funções e desempenham um papel estratégico em um tipo de finalidade em um dado momento histórico. uma grande expansão da rede privada da educação pós ensino médio, de forma que, em 1960, das matrículas globais da graduação, $40 \%$ era da rede privada, passando para $63 \%$, em 1980, e, a partir de 1994 , alcança $65 \%$ das matrículas globais.

O Brasil registra, atualmente, "2,3 milhões de alunos matriculados, dos quais 1,32 milhão está no sistema privado em geral, 410 mil nas instituições públicas federais e 400 mil nas universidades estaduais públicas" (Trindade, 2001, p. 26). A massificação e a privatização do ensino superior é um fato mundial, e, de acordo com Trindade (2001), o primeiro ocorre de modo mais lento no Brasil, porém o segundo fenômeno tem, no caso brasileiro, um exemplo perverso, pois "combina um sistema público de alto nível (apesar da crise progressiva de financiamento do Estado, a partir da Nova
República, em 1985) e a hegemonia das instituições privadas de baixa qualidade" (Trindade, 2001, p. 27).

A proposta de colocar em cena uma universidade particular de uma região interiorana do RS representa a possibilidade de refletir sobre a constituição dos sujeitos e de seus ideais profissionais num contexto que entrelaça a precarização do trabalho com a falta de expansão da rede pública de ensino superior. Dessa maneira, pretende dar visibilidade à história desses universitários, que, por sua condição mais aproximada da base da pirâmide social e mais distante dos recursos culturais da capital, compõem uma população relativamente confinada e silenciada.

O percurso do trabalho apóia-se no pensamento de Foucault, para quem o poder articulado ao saber atravessa o tecido social, circula pelos capilares mais estreitos até alcançar os lugares mais recônditos e inscrever-se no comportamento dos sujeitos. "Como um conjunto de ações sobre ações possíveis, opera sobre um campo de possibilidades, mas é sempre uma maneira de atuar sobre o(s) sujeito(s) atuante(s)" (Foucault, 1998, p. 15).

Os formandos em questão fazem parte de um contingente de indivíduos que partilham instituições, comunidades, escolas, universidades, enfim, elementos diversos, que, tal qual num jogo, mudam de posição, modificam suas funções e desempenham um papel estratégico em um tipo de finalidade em um dado momento histórico. São eles subjetivados por dispositivos e apropriamse dos modos de subjetivação colocados na cena contemporânea, a eles se submetendo 
1 Dados revelados pelo trabalho O Ciclo de Financeirização e a Nova Polarização Social, que pesquisa causas do empobrecimento da classe média brasileira, elaborado pela Secretaria do Desenvolvimento, Trabalho e Solidariedade da Prefeitura de São Paulo e que aponta que o Rio Grande do Sul apresenta comportamento semelhante ao resto do país. Através desta pesquisa foi possível verificar que, em 2001, havia no território gaúcho 17.991 pessoas com formação universitária em sub-ocupações, enquanto no país o número era 425.292 Dados encontrados no trabalho acima citado e publicados na FolhaOnline, São Paulo, por Gilberto Dimenstein em 17 de outubro de 2003. ou resistindo, e assim, simultaneamente como sujeitos e objetos, participam dos jogos de verdade sobre a educação superior e das oportunidades de ascensão social através do trabalho destinado ao nível superior.

A discussão do estatuto das verdades será feita por meio do conceito foucaultiano de regime de verdades. Segundo Revel (2002), a temática dos "jogos de verdade" está presente em toda a obra de Foucault desde o momento em que o autor se dispõe a analisar as condições de possibilidade da constituição dos objetos de conhecimento e dos modos de subjetivação, considerados indissociáveis. Na medida em que a subjetivação é dependente da objetivação e vice-versa, a descrição do desenvolvimento mútuo e de suas ligações recíprocas é precisamente aquilo que Foucault chamou de jogos de verdade.

Mesmo que a realidade contrarie as expectativas, o curso superior continua a receber um pesado investimento dos alunos e de seus familiares, independentemente do preço a ser pago pelo percurso, pois os projetos de vida são fundados na aposta feita na carreira de nível superior. O valor nominal do diploma para fim de ingresso ou reingresso no mundo do trabalho não é avaliado senão ao final do curso, quando podemos observar o abismo entre realidade e projeto. As estatísticas mostram que, ainda que aceitem ocupações aquém de suas qualificações, muitos indivíduos, ao sair da universidade, não conseguem trabalho: de 1992 a 2001, o total de desempregados com ensino superior completo, na região metropolitana de Porto Alegre, aumentou de 2055 para 6408, o que representa um acréscimo de 116,9\% ${ }^{1}$. Em 2001, no Brasil, aqueles possuidores de curso superior que trabalhavam em atividades abaixo de sua qualificação atingiam a cifra de 425,300 (Pochmann, 2002). Também é importante salientar aqui a especificidade da questão da posse do capital cultural. Bourdieu (1979) formulou esse conceito para analisar a desigualdade de desempenho escolar de crianças oriundas de diferentes classes sociais, procurando relacionar o "sucesso escolar" (isto é, os benefícios que as crianças das diferentes classes podem obter no mercado escolar) com a distribuição desse capital específico entre as classes. Tal contribuição rompe o pressuposto que considera o sucesso ou fracasso escolar efeitos de "aptidões naturais" (Catani \& Nogueira, 1998, p. 9), e marca as trajetórias dos formandos.

Traçadas as linhas gerais deste trabalho, objetivamente, o mesmo pretende trazer à discussão as expectativas de ingresso no mercado de trabalho no contexto das trajetórias de vida de seis formandos de Psicologia de uma universidade privada do interior do Rio Grande do Sul. Nossa amostra foi constituída por cinco mulheres e um homem, e buscou estabelecer relações entre as trajetórias de vida, a escolha profissional e os dispositivos que, através dos jogos de verdades, contribuem para a constituição do ideal profissional desses quase "doutores".

O propósito, estando no campo, foi buscar os relatos das trajetórias de vida centrando a atenção na constituição do projeto profissional. O sujeito, ao falar, ocupa o lugar de "dono do seu destino", como é pensado na lógica que faz funcionar a sociedade liberal. Ao narrar sua vida, descreve como se posiciona diante das condições tem para 
realizar suas escolhas e das vicissitudes que dela decorrem, ou seja, de como se apropria dos regimes de verdade para construir sua trajetória profissional.

\section{Estratégia de pesquisa}

Na busca do entendimento das expectativas de inserção profissional dos formandos de Psicologia, tomamos como suporte a perspectiva metodológica da abordagem biográfica, conforme descrita por Cabanes (2000) e Bertaux (2003), e, para análise dos relatos, as ferramentas descritas por Foucault (2000), em sua Arqueologia do Saber, onde ele considera que os enunciados devem ser compreendidos em sua situação singular de existência e aparecimento.

Na abordagem biográfica (Bertaux, 2003), o objetivo é buscar compreender um mundo social ou uma categoria de situação, e o relato de vida é considerado o de práticas em situação que falam dos contextos sociais ao seio dos quais tais práticas se inscrevem e com os quais elas contribuem para reproduzir ou transformar. No caso desta pesquisa, a categoria de situação é ser formando de Psicologia, ou, dito de outra forma, é tornar-se "doutor".

A escolha da abordagem da trajetória de vida, tal qual descrita por Cabanes (2000), foi fundamental para possibilitar a visão (des)disciplinarizada do estudo da constituição dos sujeitos.
A escolha da abordagem da trajetória de vida, tal qual descrita por Cabanes (2000), foi fundamental para possibilitar a visão (des) disciplinarizada do estudo da constituição dos sujeitos. Inicialmente, trabalhar com trajetória de vida foi uma decisão tomada porque, "ao abordar o coletivo pelo individual, ela permite entrar em contato com os aspectos menos visíveis da vida social e facilita o estudo da interação dos sujeitos com o seu meio social" (Cabanes, 2000, p. 463).
No decorrer das entrevistas, foi possível perceber que a técnica utilizada, ao deixar o sujeito falar livremente, a partir de apenas uma indução, no caso, a pergunta "Eu gostaria que tu me contasses como resolveste te tornar psicólogo", desencadeou uma forma de reflexão sobre as razões da escolha profissional, as condições possíveis para a efetivação da escolha e as ambições e frustrações que marcam as trajetórias. Por sua vez, a análise dos relatos deu lugar a uma outra forma de reflexão, a partir de, como diz Foucault, um estado de suspensão dos saberes instituídos, na qual estivemos atentos para os enunciados que compõem as formações discursivas que atravessam as narrativas.

Nesse tipo de propósito, a partir de Foucault, em sua Arqueologia do Saber, o discurso é visto como um bem finito, limitado, útil, desejável, que tem regras de aparecimento e também condições de apropriação e de utilização; é um bem que coloca, desde sua existência (e não apenas de suas "aplicações práticas"), a questão do poder, um exercício que é, por natureza, objeto de política.

Assim, seguindo com Foucault, a análise dos enunciados e das formações discursivas busca estabelecer uma lei de raridade, que repousa no princípio de que nem tudo é sempre dito. Mesmo que sejam numerosos, os enunciados estão sempre em déficit. Dessa forma, os enunciados são estudados no limite do que não está dito, na instância que os faz surgirem à exclusão de todos os outros (não se trata de fazer falar o mutismo, ou de estudar os obstáculos que impediram tal descoberta, recalcaram tal forma de enunciação, tal significação inconsciente ou tal racionalidade em devir). 
Em Foucault, a formação discursiva não carrega consigo um discurso "não dito", mas uma distribuição de lacunas, vazios, limites, recortes.
Em Foucault, a formação discursiva não carrega consigo um discurso "não dito", mas uma distribuição de lacunas, vazios, limites, recortes. Essas lacunas não estão ligadas à repressão, de modo que, sob os enunciados manifestos, algo permanece oculto. O domínio enunciativo está inteiro em sua própria superfície e ocupa um lugar que só a ele pertence. A descrição consiste em constatar a posição singular que ele ocupa, que ramificações, no sistema das formações, permitem demarcar sua localização e a forma como ele se isola na dispersão geral dos enunciados. Afirma ainda Foucault (2000, p. 138) que os enunciados são transmitidos e conservados, têm um valor, e os sujeitos buscam deles se apropriar, repeti-los, transformá-los e darIhes uma posição dentro da instituição.

Em resumo, para o autor da Arqueologia do Saber, a análise das formações discursivas se volta para essa raridade e toma-a como objeto explícito. Se a interpretação é uma reação à pobreza enunciativa, analisar a formação discursiva é procurar a lei de sua pobreza, e, em um sentido, pesar o "valor" dos enunciados Esse valor não é definido por sua verdade, pela presença de um conteúdo secreto, mas caracteriza o seu lugar, sua capacidade de circulação e troca, sua possibilidade de transformação, não apenas na economia dos discursos mas também na administração dos recursos raros.

\section{O cotidiano do curso e as expectativas quanto ao futuro}

Durante o curso, os alunos freqüentaram as aulas à noite e, durante o dia, desenvolveram atividades como funcionários em empresas privadas da região até o momento em que as exigências dos estágios curriculares se tornaram inconciliáveis com as demandas dos empregadores. Nessa ocasião, aqueles que ainda não tinham utilizado o crédito educativo se viram forçados a lançar mão desse recurso, através do qual passaram a pagar 30\% do valor das mensalidades.

Adquiriram, com o diploma, uma dívida a ser paga, hipoteticamente com o resultado do trabalho decorrente de sua formação profissional, em seis anos, com um ano de carência após o término do curso. Muitos dos alunos estão realizando o sonho de cursar uma universidade tardiamente, e alguns têm família constituída, com todas as responsabilidades que isso implica.

As entrevistas, como já dito, foram realizadas nas dependências da própria faculdade, com seis alunos, num período imediatamente anterior à formatura. A acolhida oferecida pelos estudantes transmitia uma sensação de expectativa e curiosidade. O fato de se ter um encontro marcado para o horário da tarde, fora do horário das aulas, em um prédio retangular e confortável, mas de arquitetura simples, completamente vazio, sem biblioteca aberta ou sequer um quiosque que realizasse fotocópias, transmitiu a impressão de isolamento e estagnação.

O portão principal da universidade está em face ao cemitério local, e o lateral, que dá ingresso ao amplo estacionamento da instituição, em meio ao vazio da região, está encimado pelas palavras de pórtico: O Futuro já Começou. 
O slogan capta como promessa de futuro um dos anseios mais fundamentais construídos na modernidade: a busca de algo que possa apaziguar a inquietude que atravessa a existência. Essa angústia de incompletude e solidão, representada pela impotência humana diante de seu desamparo, móvel de seu "apego apaixonado a quem depende" (Butler, 2002), é, ao mesmo tempo, garantia do permanente movimento da vida em direção ao amanhã, à mudança, à vida adulta, sendo esta considerada, na cultura ocidental contemporânea, como a capacidade do indivíduo para amar e trabalhar, e que, descritivamente, é a condição necessária para sua integração na rede de laços sociais.

Ao falarmos de trabalho, é importante marcar que a noção de trabalho recobre uma pluralidade de regiões da realidade (Ruffino, 2000, p. 178). Assim, para cada indivíduo, o termo tem diversos sentidos, trabalho de apropriação dos modos de subjetivação colocados em cena conforme as condições de possibilidade de cada ser em particular (processo de subjetivação) e trabalho como forma de inscrição social, aquele que vem ocupando um lugar central na vida dos sujeitos em sociedade. Conforme Castel (2001), o trabalho tem estruturado, inteiramente, na modernidade, a formação societária, cujos atributos vêm se impondo sobre outros suportes da identidade, como o pertencimento familiar ou a inscrição numa comunidade concreta, além de caracterizar o status que situa e classifica o indivíduo. No entanto, podemos afirmar que, a partir dos anos 90, mesmo que tenha havido um aumento da taxa de desemprego para trabalhadores com escolaridade de nível superior, esta continuou a ocupar um lugar idealmente investido. A escolaridade superior representa ainda a possibilidade de modificação ou manutenção do status social, de forma que a presença da Universidade no interior, através de um curso noturno, atende uma demanda dos sujeitos filhos de operários que lá se encontram radicados, ao mesmo tempo em que sustenta a utopia de mobilidade social para essa população de trabalhadores assalariados, mais próximos da base da pirâmide social.

Os sujeitos se colocam em processo, realizando o trabalho psíquico de renunciar a algo, no presente, por uma satisfação postergada que se apresenta como maior, ou melhor. Constroem um projeto e apostam seus recursos, sua energia, seu tempo, seus sonhos, em busca daquele trabalho, distinto do que executavam, e que teria valor maior no mercado, um trabalho através do qual eles poderão ter os objetos por meio dos quais poderiam se ver mais bem situados dentro da sociedade que associa sucesso e status à propriedade de bens ou mercadorias para além de sua funcionalidade, trabalho através do qual eles poderiam ser diferentes do que foram até hoje. Conforme Holanda (2005), em Raízes do Brasil, o título de "doutor", tem, historicamente, marcado uma posição superior na vida social, a partir da qual o trabalho intelectual tem tido um valor maior que o trabalho manual.

\section{Tornar-se "doutor": ilusão ou possibilidade?}

No caso dos formandos entrevistados, provenientes de vários municípios da região, alguns mais próximos, outros um 
pouco mais distantes, o que foi decisivo na escolha desse curso e dessa localidade foi a possibilidade de cursar Psicologia à noite. Deslocaram-se dentro de um espaço e de uma velocidade que thes era possível e que permitia a perseguição de um ideal, aquele de ser psicólogo.

Desde o período intermediário do curso, quando necessitaram buscar estágios, e mais explicitamente no final do curso, diante da perspectiva de dar continuidade ao seu projeto profissional, evidenciase, na contramão da globalização e da flexibilização, uma "localização". As palavras dos alunos confirmam a impressão de que esse é um mundo social onde a vida é rotineira, com acesso restrito a recursos culturais cosmopolitas e que o deslocamento tem mão única, ou seja, a Universidade vai até o interior oferecer o seu produto, mas o interior não se enriquece a ponto de adquirir mobilidade e recursos para concorrer no mundo globalizado. Conforme Bertaux (2003), um mundo social se constrói em torno de um tipo de atividade específica, que pode ser uma atividade profissional como a do padeiro artesanal ou a do taxista. Ao recolher diversos testemunhos, teremos descrições, desde o interior, de diversos microcosmos e de lógicas de passagem de um para outro. A hipótese é que as regras que controlam o mesocosmo ou conjunto do mundo social são igualmente ativas nos microcosmos que a compõem, e, assim, a observação de um destes permite observar as lógicas do conjunto social pelos mecanismos de reprodução e transformação dos microcosmos (Bertaux, 2003, p. 13). No caso em apreço, considera-se mundo social o conjunto de estudantes do interior do Estado, e, como recorte para viabilizar a pesquisa, a categoria de situação constituída no fato de serem formandos do curso de Psicologia.

Assim, uma das formandas, Manuela, de 24 anos, ao narrar sua trajetória de vida, relata que, durante o curso, já havia conseguido alugar apartamento e morar em Porto Alegre, mas que, pela necessidade de realizar estágios, viu-se obrigada a retornar para sua cidade. Ali podia morar com os pais. Além do mais, estes, por serem funcionários públicos de nível médio, tinham relacionamentos na comunidade e conseguiram um estágio remunerado para ela. Essa mesma formanda tem como desejo dedicar-se à clínica, e pensa que, para isso, deve fazer um curso de especialização na capital, mas, como necessita se manter e pagar o crédito educativo, cogita aceitar trabalho junto a um presídio da região, onde seus pais e outros parentes, tios e primos, trabalham como agentes penitenciários. Nunca foi sua intenção trabalhar com Psicologia forense, mas passa a pensar que essa poderá ser uma boa estratégia para trabalhar como psicóloga, considerando as condições que possui para traçar seu futuro profissional.

Outra moça, Joana, de 39 anos, mulata, filha de operários, comenta que "tudo é em Porto Alegre", e, considerando que precisa pagar o crédito educativo e alugar um espaço para o exercício da clínica numa população que tem poucos recursos para remunerar uma consulta, pensa em aceitar empregos fora de sua área, como aquele que tinha antes de realizar o curso, talvez dentro da mesma empresa distribuidora de bebidas, pois não pode ficar sem ter algum ganho. 
Percebo que os lugares se invertem: de alguém que chega para solicitar uma colaboração,

com temor de

causar transtorno na rotina de estudos do grupo, passo a ocupar o lugar de alguém que pode oferecer algo e que

prestigia o grupo com sua presença.
Joana foi o meu primeiro contato com os alunos; foi solícita e organizou os colegas para realizarem as entrevistas, colocandome em contato com os demais alunos. Como demonstrasse uma expectativa ansiosa com a minha chegada, senti-me como alguém que pudesse oferecer alguma coisa que alterasse "a rotina de todos os dias". Percebo que os lugares se invertem: de alguém que chega para solicitar uma colaboração, com temor de causar transtorno na rotina de estudos do grupo, passo a ocupar o lugar de alguém que pode oferecer algo e que prestigia o grupo com sua presença. A solicitude de Joana faz-me refletir sobre o lugar social marcado pela cor, associado à questão de classe, pois ela tem outras razões para valorizar simbolicamente sua conquista universitária.

A vulnerabilidade do projeto profissional de Joana é intensa a partir da imposição do trabalho como fonte de sobrevivência desde cedo. Empenhada em fazer a travessia em busca de outra inserção no mercado de trabalho, cursa toda a universidade numa demonstração de força e persistência na luta contra os obstáculos, e, para orgulho dos pais, torna-se "doutora". Agora se sente posta à prova:

Quando eu entrei, tinha outra perspectiva, imaginava que depois, mais pro final do curso, seria diferente, só que hoje mudou totalmente. Eu tenho sentido que tá muito difícil entrar pro mercado de trabalho, até porque, no semestre passado, eu tive que sair; eu trabalhava numa empresa há 9 anos. Eu trabalhava 10 horas por dia e depois vinha para cá. Em janeiro e fevereiro, às vezes a gente saía às dez da noite, era cansativo... Aí eu ficava só com as explicações da aula, porque não dava pra revisar todas as matérias. Era muito atropelado. Eu tive que sair por causa do horário do trabalho. Quando chegou o momento decisivo, o patrão disse: "Não vai dar mais pra ti, o horário". Eu disse: "Se eu trabalho cinco horas por dia!", e ele disse: "E o sábado?"; eu falei que tinha uma cadeira que era sábado o dia inteirinho, e aí ele disse que não ia dar. Eu queria fazer estágio. Foi uma decisão muito difícil, e o pai disse: "Não te preocupa, que o pai te ajuda". E eu tomei a decisão.

O futuro de Joana, psicóloga, traz a indagação se conseguirá produzir uma nova condição de vida e trabalho ou estará, por suas marcas anteriores, destinada à mera reprodução do que foi o caminho dos pais, uma vez que o acesso ao curso superior chega em um momento no qual o mesmo perde valor de mercado.

Vânia, uma senhora de 43 anos, casada e com filhos adolescentes, que é professora de primeiro grau, acreditava que, ao concluir o curso, poderia ter uma progressão funcional em sua escola e trabalhar como psicóloga escolar. Agora, ao final do curso, ofereceramIhe uma função relacionada com sua formação, mas deve permanecer no mesmo nível funcional e salarial que teve até hoje, em desvio de função. Relata sua decepção e a sensação de perda de tempo, pois levou sete anos e meio para concluir o curso. Diz que foi muito "duro" educar três filhos pagando ULBRA, com a renda de professora de ensino fundamental e o ganho do marido, que é funcionário de um banco estadual. Vânia acrescenta um comentário:

É muito difícil; até os professores questionaram porque o curso não está rendendo, está sendo desativado. Eu acredito que seja mais a questão financeira, porque é um curso muito caro para a nossa região, a gente tá fazendo com muito sacrifício, e tu não desiste... 


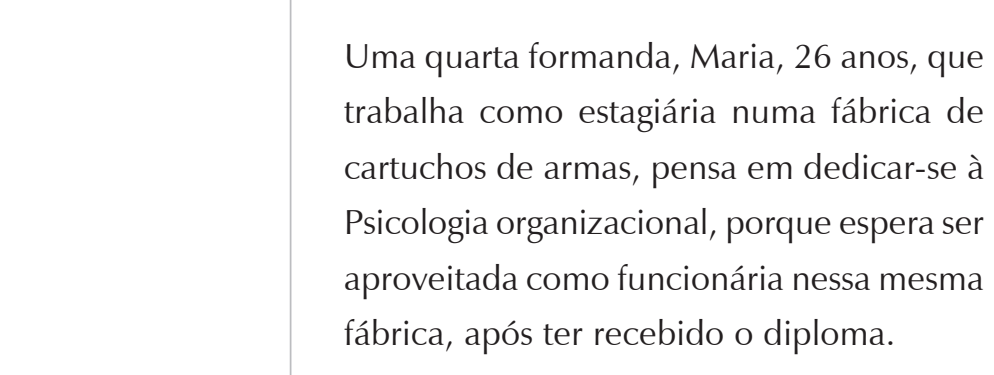

A falta de recursos para a mobilidade fixa domicílios. A globalização propõe a mobilidade, e a comunicação viabiliza a dissipação das distâncias, mas a distribuição da mobilidade é desigual, e perpetua as desigualdades e estratifica os sujeitos.

\section{Estudar psicologia: um percurso individualizante}

A identidade almejada de "ser psicólogo", isto é, a construção das expectativas de inserção no mercado como psicólogos, na maioria dos casos, está vinculada ao trabalho em clínica, entendida como clínica psicanalítica, um ideal cujo currículo acadêmico auxilia a construir, e porque o imaginário popular vincula sucesso, autonomia e dinheiro ao exercício da clínica, que correspondia a uma realidade hoje não mais vigente.

A Psicologia é definida a partir de uma rede enunciativa que atravessa as falas, e emerge como uma disciplina destinada aos cuidados,

Anseio de pais e filhos, o ideal de um curso superior representa a fuga de um destino social. à palavra, à escuta, ao entendimento e à mitigação da dor psíquica dos sujeitos individualmente. Alguns formandos relacionam a escolha do curso de Psicologia com a habilidade que consideravam ter para escutar, dar conselhos, sintonizar com a dor do outro, numa vivência dentro da família, como na história de Francisca, que acompanhou o irmão adito a drogas, ou, como relata Joana, dentro do trabalho assistencial que realizou na Igreja Assembléia de Deus, à qual pertence.
A Psicologia social não é considerada uma perspectiva teórico-aplicada de direcionamento da inserção profissional, pois aparece nos relatos associada à pobreza e ao assistencialismo. Trabalhamos com a idéia de que a Psicologia social, ao tratar de questões como a desigualdade social, por exemplo, aproxima os formandos do capital de experiência biográfico, do qual eles procuram se distanciar com a formação universitária. A perspectiva da clínica individualizante, tal como aprendida no curso, a partir de uma cisão entre o social e a clínica, produz um afastamento de seus pares nos moldes da distinção, tal como descrita por Bourdieu (1979). Com exceção de um caso, todos os formandos são filhos de operários, funcionários de nível médio, ou pequenos comerciantes, cuja subsistência correspondeu a muitos anos de luta e trabalho, e a uma vida onde "não faltou nada", mas na qual as restrições foram significativas. Nessa trajetória, o formando aparece como o primeiro a ter diploma de nível superior ou então pertence à primeira geração a alcançá-lo.

Anseio de pais e filhos, o ideal de um curso superior representa a fuga de um destino social. Separados do passado, sem o amparo de uma tradição que sinalize a Universidade como uma caminhada já percorrida em gerações anteriores, o ideal de ser psicólogo, com exceção de uma situação relatada, não segue modelos identificatórios próximos, mas surge como a aposta de quem compra o slogan de que o futuro está na Universidade, e a carreira de nível superior aparece como a via de ascensão social prioritária, uma opção que tem um custo elevado, sendo maior a dívida material que a simbólica. 
Não havia, por parte das famílias, uma cobrança com relação ao curso superior como existe em outros estratos sociais, de forma que os alunos não sentem que deviam aos pais a formatura. Essa trajetória foi realizada por decisão dos mesmos, que assumiram as responsabilidades e os riscos de tal empreitada, como a dívida do crédito educativo e o risco de abandonar o emprego para realizar os estágios. Os familiares participaram dessa trajetória como coadjuvantes, e obtiveram uma satisfação vicariante com o êxito da filha, da neta ou da sobrinha, expresso nas palavras de um parente: "Ela mesma disse, esses dias, pra minha vó: tu vê só, tu vai tê uma neta formada, né..."

A observação concreta dos sujeitos em pesquisa revela que fatores fora do âmbito da família contribuem para a constituição do ideal profissional, do mesmo modo que os intrafamiliares, mas que estes se constituem, muitas vezes, em negociações, mais do que em identificações propriamente ditas: "as famílias são os lugares onde se efetuam as negociações, as arbitragens, as microssínteses e as transações entre as diferentes lógicas." (Bertaux, 2003, p. 43).

A família aparece, na formação dos planos futuros, como fonte geradora de motivação para o trabalho, constatação que coincide com os estudos de Colbari (1995) sobre a ética do trabalho, nos quais encontramos:

...Cabe ressaltar que a inserção dos filhos na esfera sentimental e afetiva da família não subestima a realidade da mesma como "agência da sociedade", instância de controle que garante as funções de reprodução e interiorização da autoridade. A família preserva sua condição de instituição privilegiada de controle social, atuando na formação da personalidade da criança e na integração da personalidade do adulto: garante a integridade do grupo familiar e o padrão disciplinar por ele interiorizado. Desse ponto de vista, a família contribui para a "manutenção ou o estabelecimento de hábitos e valores que favorecem o ingresso no mercado regular" (Durham,1984, p. 210), o que, segundo Habermas (1984), compromete a realização de uma concepção de família como reino da humanidade, da liberdade, do amor e das relações "puramente humanas", para reforçar a sua concepção enquanto instância racionalizadora e integradora das relações sociais. (p. 139)

Outros elementos extrafamiliares afetam as escolhas profissionais dos alunos. Encontramos expressão destes na função da Universidade no imaginário social ou na vivência como pacientes de psicoterapias, através das figuras dos professores ou dos terapeutas.

Do ponto de vista de Cabanes (2000), verificamos que, no que se refere às questões identificatórias, o autor amplia a noção do ideal do Eu, originariamente definida pela psicanálise, para o ideal do Nós (tal como trabalhada no campo da análise dos relatos das trajetórias de vida, ou seja, retirando da análise a dimensão inconsciente) e oferece, assim, uma forma de pensar a produção conjunta do individual e do social, pois, segundo ele, a memória coloca em relação o sujeito, tal qual ele é em sua complexidade, e o mundo social. Assim, no dizer de Cabanes (2000),

Pode-se pensar essa continuidade na relação indivíduo/sociedade baseandose na substituição no imaginário do "Ideal do Eu" pelo "Ideal do Nós" e da troca simbólica entre os dois ideais. Um encadeamento sem princípio nem fim englobaria a totalidade do ciclo de vida: 


\begin{abstract}
identificação primária ao pai (ser como ele) e constituição do Eu, identificação secundária (tomar seu lugar) e constituição do ideal do Eu, identificação primária com o Chefe e constituição do Nós, identificação secundária e constituição do ideal do Nós que é o princípio da formação das instituições que, por sua vez, formam os pais, vetores da situação edipiana. Essa troca simbólica entre ideal do Eu e ideal do Nós se estrutura, na vida social, sobre o conceito de apoio: não é a saciedade de uma necessidade vital (constituição do nós), mas a satisfação de outra coisa que é uma demanda de amor. Os regimes dessa demanda são socialmente identificados, e, conforme C. Geofrey, são três, e passam pelas figuras do Chefe, do Mestre e a Lei. (p. 5)
\end{abstract}

A questão da constituição do laço social aporta uma reflexão sobre as possibilidades de transformação que cada sujeito pode realizar sobre si na passagem da família para a sociedade. Aquela, sendo a primeira célula do desenvolvimento social, é também matriz constitucional, pois, pela dependência que o desamparo humano obriga, é, geralmente, sede daquilo que Butler (2002) vai mostrar ser "um apego apaixonado ao assujeitamento", e que exerce um constrangimento sobre as escolhas que um indivíduo pode fazer.

(2002), embora o assujeitamento seja constitutivo, a transformação das condições nas quais o sujeito está inscrito é possivel, pois a repetição nunca se apresenta exatamente da mesma maneira.

Para Butler (2002), embora o assujeitamento seja constitutivo, a transformação das condições nas quais o sujeito está inscrito é possível, pois a repetição nunca se apresenta exatamente da mesma maneira. Essa repetição, ou melhor, essa reiteração (no sentido foucaultiano), e, portanto, "o sujeito pode fazer-se objeto de uma fabricação ulterior" (Butler, 2002, p. 157). É importante ressaltar que Butler define resistência como a resistência à norma e que diz respeito à posição do indivíduo diante dos disciplinamentos impostos pelas redes de poder-saber.

Verificamos, pois, que, além da possibilidade de novas identificações sociais, como pontuado por Cabanes através da noção do Ideal do Nós, com uma atração para a norma disciplinarizante transmitida pelas instituições, o sujeito encontra a possibilidade, para além do assujeitamento à norma, de transformação de si através da reflexão ética, que, em Foucault (2001c, p. 1530), "é a prática reflexiva da liberdade".

Embora exista a possibilidade de mudança das condições de sujeição na reinstalação do poder, o não questionamento da troca de posição no social que se coloca no lugar do coletivo não resiste, pois o mercado se encarrega de recolocar as condições de assujeitamento. à qual o sujeito está atado, por seu caráter incompleto, é sua coerência, e, ao mesmo tempo, sua incoerência: "ela é o não lugar da subversão, ela garante a possibilidade de re-incarnação da norma assujeitadora suscetível de dirigir de outro modo sua própria normatividade", havendo, nessa diferença, a possibilidade de resistência

\section{Como aponta Castel e Haroche (2001):}

Abordando o princípio de igualdade entre os indivíduos, em particular sob a forma de igualdade de oportunidades, as sociedades democráticas individualizam a desigualdade: se o jogo é aberto e todo mundo pode concorrer e se classificar de acordo com seu mérito, o fracasso é imputável ao próprio indivíduo. (p. 93, tradução nossa)

É possível, portanto, entender que a constituição societária, cujo discurso anuncia a igualdade de oportunidades para sujeitos desiguais, traz como resultado 
A Universidade larga elas aos ventos, assim, sabe, então, o fato de participá, de fazê parte de uma classe que tenha esse senso comum... Essa imagem, isso, no caso, me desilude... diante daquela perspectiva que eu tinha em termos de profissão... um aplacamento da reflexão ética e um engajamento frágil dos indivíduos a ser vencido, já que a situação é tomada como uma condição particular do sujeito, como ser filho de operário, por exemplo, e não aparece como uma questão coletiva. Nesse caso, a Universidade aparece como uma prestadora de serviços à comunidade, e fica reduzida a uma pura "mediadora" que apenas reproduz a comunidade tal qual ela está arranjada, "sem nenhuma crítica e com bastante anacronismo" (Orlandi, 1993, citado por Silveira, 2004, p. 31).

Nesse sentido, todos os formandos, com exceção de um, estão na mesma situação, e relatam uma trajetória de vida que pode ser chamada de típica. São todos estudantes de Psicologia de uma universidade paga, com exceção de um, todos lançaram mão do crédito educativo, tiveram incompatibilidade entre os estágios curriculares e as exigências de seus empregadores, sofreram restrições e contaram com o apoio, mesmo que modesto, das famílias, dentro do que Castel (2001) descreve como suportes aproximados. Castel (2001) utiliza o termo suporte como condição objetiva de possibilidade, como a capacidade de dispor de reservas que possam ser do tipo relacional, cultural ou econômica, etc., e que são arrimos sobre os quais pode se apoiar a possibilidade de desenvolver as estratégias individuais. Os formandos gostariam de fazer especializações em Porto Alegre, mas estão localizados, pois não têm recursos para vencer a distância, cujo custo para eles é elevado. São unânimes em afirmar que "têm certeza de que este é o lugar em que queriam estar", embora os temores com relação ao futuro profissional sejam fonte de angústia e insônia para a maior parte deles.
Uma das alunas, que havia começado um outro curso em uma universidade maior, afirma que ali, no interior, existe solidariedade entre os colegas, que todos professores conhecem os alunos e que, no outro curso, "ninguém emprestava uma anotação para xerox, e, se perdia uma matéria, tinha que se virar, pois ninguém ajudava em nada". Essa reflexão expressa que existe solidariedade, mas esta se dá em nível de auxílio inter-relacional, numa forma de socialização que ocorre privilegiando as trocas individuais, o que confirma o frágil engajamento no laço social.

A socialização, conforme descreve Gauchet (2002),

...designa o processo pelo qual se aprende a se olhar como um entre outros (à se regarder comme un parmi d'autres). Trata-se da ocorrência do eu, mas isso poderia ser qualquer um. Aprendizagem da abstração de si que cria o senso do público, da objetividade, da universalidade, aprendizagem que the permite se colocar no ponto de vista do coletivo, abstração feita de implicações imediatas. (p. 244)

O aluno que representa uma exceção parcial por contar com capital cultural chama-se Pedro, tem 43 anos, e coloca-se como alguém fora e acima dos demais colegas que são os novos psicólogos em sua cidade, embora não chegue a rivalizar diretamente com os de seu curso. Ele diz:

O psicólogo não adianta, tu chega lá e, é umas menininhas assim novinhas, despreparadas, no caso, com essa profissão, e então, acaba criando, assim, um senso comum de que a Psicologia são essas que saem despreparadas, sem uma técnica própria... A Universidade larga elas aos ventos, assim, sabe, então, o fato de participá, de fazê parte de uma classe que 
tenha esse senso comum... Essa imagem, isso, no caso, me desilude... diante daquela perspectiva que eu tinha em termos de profissão...

Descreve sua decepção com o valor social atribuído à profissão de psicólogo, mas responsabiliza os colegas individualmente, e comenta, com relação ao mercado de trabalho na atualidade:

Como autônomo, os profissionais estão se digladiando, competindo, passando um por cima do outro, assim meio com falta de ética... Em termos de emprego, no último concurso da CEF, havia 956 vagas, e inscreveram-se 6000 candidatos, possivelmente muitos com curso superior concorrendo para vaga de nível médio, e isso traz muito sofrimento para o ego.

Pedro é exceção parcial à regra, pois, por contar com o auxílio de uma tia, não precisou do crédito educativo. Ele se coloca como alguém "que já deu certo", pois tem um emprego de psicólogo que o espera em sua cidade, onde somará 20 horas de trabalho como psicólogo às 30 horas de trabalho que já executa como bancário. Pedro evoca, como descreve Gauchet (2002), a principal característica da personalidade contemporânea:

O indivíduo contemporâneo seria, em sua maneira de ser, o primeiro indivíduo a viver ignorando que vive em sociedade, o primeiro indivíduo a poder se permitir, pela evolução mesmo da sociedade, ignorar que ele está em sociedade. $\mathrm{O}$ indivíduo contemporâneo seria o indivíduo desconectado simbolicamente e cognitivamente do ponto de vista do todo, o indivíduo para o qual não existe mais sentido se colocar no ponto de vista do conjunto. (p. 254)

\section{Conclusão}

Embora relatem seu sofrimento por perceberem que as condições que haviam imaginado para a conclusão do curso tenham se transformado, os formandos percebem a situação pelo lado positivo. A partir da possibilidade de serem chamados de doutores, valorizam o aspecto de ascensão social representado pelo trajeto universitário. A situação de vulnerabilidade, por ser tomada como uma condição individual, é discutida e sofrida apenas nessa perspectiva.

No relato das trajetórias de vida, o sujeito emerge isolado, apartado das condições coletivas de sua existência, donde podermos afirmar a existência de um lugar de onde o sujeito fala, dentro da Universidade e no conjunto societário como um todo, e cuja enunciação reforça a lógica individualizante e do mérito.

Entendemos que o discurso mercantilista sobre a educação superior "objetifica" os formandos, transformando-os em consumidores endividados na compra de um diploma de graduação, e que, por estarem subjetivados nesse jogo de verdades, consideram que esse é o lugar onde queriam estar. Pensamos também que exista uma relação de associação entre uma formação psicológica centrada em determinado tipo de clínica individualizante (que não valoriza as trajetórias de vida dos estudantes) e a rede enunciativa constituinte do regime de verdades que produz a captura identitária em torno do que é idealizado como a essência da Psicologia.

Acreditamos que a visibilização de trajetórias marcadas por promessas de cunho mercantil 
Objetivo principal atualmente seja não o de descobrir o que somos, mas o de recusar aquilo que somos.

É preciso que possamos imaginar e construir aquilo que poderemos ser para nos liberar do "duplo constrangimento" político que são individualização e totalização simultâneas das estruturas do poder modernas. $(p$. que se utilizam do sonho universitário, alimentado pela desigualdade social, possa fazer com que a construção de expectativas de inserção profissional não esteja atrelada à lógica do mesmo e da reprodução. Para concluir, é importante marcar, em concordância com Foucault (2001b), que o poder carrega em si a própria resistência aos dispositivos assujeitadores e que, assim, inclui a possibilidade de transformação, na qual:

O objetivo principal atualmente seja não o de descobrir o que somos, mas o de recusar aquilo que somos. É preciso que possamos imaginar e construir aquilo que poderemos ser para nos liberar do "duplo constrangimento" político que são individualização e totalização simultâneas das estruturas do poder modernas. (p. 1051). 


\section{Silvia Maria Silveira *}

Médica, psiquiatra, Mestre em Psicologia social e institucional. Instituto de Psicologia da UFRGS.

Henrique Caetano Nardi

Médico, Doutor em Sociologia pela UFRGS, prof. do Departamento de Psicologia social e institucional. Instituto de Psicologia da UFRGS.

\section{* Endereço para correspondência:}

Av. Bagé, 494, ap. 203, Bairro Petrópolis, Cep: 90460-080 - Porto Alegre-RS

E-mail:sl.sl@terra.com.br

Recebido 08/11/2006 Reformulado 14/02/2007 Aprovado 01/03/2007

\section{Referências}

Bertaux, D. (2003). Les récits de vie. Paris: Nathan.

Bourdieu, P. (1979). Distinction: la critique sociale du jugement. Paris: Minuit.

Butler, J. (2002). La vie psychique du pouvoir. Paris: Leo Scheer.

Butler, J. (2003). Problemas de gênero: feminismo e subversão de identidade. Rio de Janeiro: Civilização Brasileira.

Cabanes, R. (2000). Quelle approche biographique? Revue Internatinale de Psychologie, V/VI(14).

Castel, R. (2001). As metamorfoses da questão social: uma crônica do salário (3a ed). Petrópolis, RJ: Vozes.

Castel, R., \& Haroche, C. (2001). Propriété privée, proprieté sociale, proprieté de soi: entretiens sur la construction de I'individu moderne. Paris: Fayard.

Catani, A. D., \& Nogueira, M. A. (1998). Uma sociologia da produção do mundo cultural e escolar. In Pierre Bourdieu: escritos da educação (3a ed). Petrópolis, RJ: Vozes.

Colbari, A. L. (1995). A ética do trabalho. São Paulo: Letras e Letras.

Durham, E. R. (1984). A caminho da cidade. São Paulo: Perspectiva.

Foucault, M. (1998). História da sexualidade 2: o uso dos prazeres (8a ed.). Rio de Janeiro: Graal.

Foucault, M. (2000). A arqueologia do saber (6a ed.). Rio de Janeiro: Forense Universitária.

Foucault, M. (2001a). Le sujet et le pouvoir. In Dits et écrits II, 1976/1988. Paris: Gallimard.
Foucault, M. (2001b). À propos de la généalogie de l'éthique: un aperçu du travail en cours. In Dits et écrits II, 1976-1988. Paris: Gallimard.

Foucault, M. (2001c). L'éthique du souci de soi comme pratique de la liberté. In Dits et écrits II, 1976-1988. Paris: Gallimard.

Gauchet, M. (2002). La democracie contre elle-même. Paris: Gallimard.

Gentili, P. (Org.). (2001). Universidades na penumbra: neoliberalismo e reestruturação universitária. São Paulo: Cortez.

Holanda, S. B. (2005). Raízes do Brasil. São Paulo: Companhia das Letras.

Nardi, H. C. (2006). Ética, trabalho e subjetividade: trajetórias de vida no contexto do capitalismo contemporâneo. Porto Alegre: Ed. da UFRGS.

Pochmann, M. (2002). O emprego na globalização: a nova divisão do trabalho e os caminhos que o Brasil escolheu. São Paulo: Boitempo.

Revel, J. (2002). Le vocabulaire de Foucault. Paris: Ellipses.

Ruffino, R. (2000). Do trabalho psíquico ao trabalho social. In A. Jerusalinky, A. C. Merlo, \& A. L. Giongo, O valor simbólico do trabalho e o sujeito contemporâneo. Porto Alegre: Artes e Ofícios.

Silveira, R. (2004). A cultura do polígrafo. Dissertação de Mestrado em Psicologia Social e Institucional, Universidade Federal do Rio Grande do Sul, Porto Alegre.

Trindade, H. (2001). As metáforas da crise: da "universidade em ruínas" às "universidades na penumbra" na América Latina. In P. Gentili (Org.), Universidades na penumbra: neoliberalismo e reestruturação universitária (pp. 13-43). São Paulo: Cortez. 